\title{
Intimate Partner Abuse: Cases Involving Protective Order Violations versus Those That Do Not
}

\author{
Heather C. Melton ${ }^{*}, 1$ and Kristjane Nordmeyer ${ }^{2}$ \\ ${ }^{1}$ University of Utah, Department of Sociology, 380 S 1530 E\#301, UT 84112, USA \\ ${ }^{2}$ Westminster College, 1840 South 1300 East, Salt Lake City, UT 84105, USA
}

\begin{abstract}
This study explores police response to protective order violations and cases that do not involve protective violations within the context of intimate partner abuse. Major objectives of the study are to: 1) understand in what way protective order violations differ from other domestic violence cases that come to the attention of the police and; 2) to understand what factors lead to arrest in cases involving protective order violations and those that do not. Data from a large metropolitan area in the United States is analyzed to understand how the police are responding to these cases. Domestic disturbance calls from 2003 are examined for comparison between all domestic disturbance calls $(\mathrm{n}=1187)$ and protective order violation calls $(n=252)$. Findings include differences between these two types of calls (with protective order cases less likely to be between parties currently in a relationship, for the offender less likely to be present when police arrive, and more likely to end up in arrest) and differences and similarities in the predictors of arrest in these two types of calls. Implications for policy and future research are discussed.
\end{abstract}

Keywords: Intimate partner abuse, police, protective orders.

\section{INTRODUCTION}

Intimate partner abuse has received widespread attention over the last thirty years. In a large part, the response has come from feminist advocates putting pressure on the criminal justice system to view and recognize intimate partner abuse as a crime (Eigenberg, 2001). Before this outpouring of attention, domestic violence was viewed as a "private matter" rather than a crime against a person. In fact, prior to the early 1980 s, police officers were discouraged from making arrests in "domestic disturbances", most were instructed to mediate, separate, or refer the couple to counseling (Goolkasian, 1986). Changes have been made in all states of the United States that allow police officers to arrest domestic violence suspects (Bui, 2001). Alternatively, with raised awareness regarding intimate partner abuse, came legislation in many states authorizing the use of protective orders for domestic violence. Today, protective orders are commonly being used as a legal remedy for victims of intimate partner abuse (Carlson, Harris \& Holden, 1999; Kethineni \& Beichner, 2009; Logan \& Walker, 2009; Moracco, Andersen, Buchanan, Espersen, Bowling \& Duffy, 2010). This paper focuses on cases that come to the attention of the police that involve a violation of a protection order and those that do not. Given that police respond to intimate partner abuse calls with protective orders and those without, the goal is to explore the differences and similarities between these types of cases.

*Address correspondence to this author at the University of Utah, Department of Sociology, 380 S 1530 E\#301, UT 84112 USA;

Tel: 801-581-3108; Fax: 801-585-3784;

E-mail: heather.melton@ soc.utah.edu

\section{Protective Orders}

Protective orders are intended to prevent future acts of violence and/or threats against the victim by an intimate partner. Protective orders can be obtained in both civil and criminal courts (Kethineni \& Beichner, 2009). While there is a great deal of variation in the process and stipulations from jurisdiction to jurisdiction, in civil protective order requests, victims of abuse must apply and are required to show proof of prior violence or continued harassment to qualify for the order. Protective orders are usually issued by a county or district judge and include both temporary protective orders (also called ex-parte orders) and permanent protective orders (also called restraining orders) (Chaudhuri \& Daly, 1992). The details of protective orders vary from case to case and can include child custody or property provisions. In general, they all include at least three elements to protect the victim from the following behaviors: 1) any act of violence or threat of violence; 2) contact with the offender, either directly or through a third party, for a specified period of time (usually between 30 days and 1 year) and; 3) offender contact with the victim's residence or place of employment. Violation of any of these conditions can lead to immediate arrest, a fine, or both (Chaudhuri \& Daly, 1992; Carlson, Harris \& Holden, 1999).

Research demonstrates that protective order violations are linked to an increased risk of violence. People with protective orders are more likely to have criminal histories with a pattern of violence against people and property (Logan, Nigoff, \& Walker, 2002). Victims who have an increased risk of danger may be more likely to seek out protective orders. Logan, Nigoff, and Walker (2002) found 
that two in three stalkers had a protective order in place either before or after their stalking charges. Stalking is linked to an increased risk of violence and lethality. Because stalking behaviors lead a person to seek a protective order out of fear for safety and may be accompanied by severe physical abuse, sexual abuse, or threats, a violation of a protective order may potentially be viewed as an indicator of life-threatening behavior. In fact, one in three to four female homicides involves an intimate partner with a past history of stalking (McFarlane, Campbell, Wilt, Sachs, Ulrich \& Xiao 1999).

\section{Effectiveness}

Research on the effectiveness of protective orders is limited and results are far from definitive. In two older studies, $86-92 \%$ of the women reported that the violence had stopped after obtaining a protective order (Kaci, 1994; Keilitz, Hannaford \& Efkeman, 1997). A more recent study found that while half the protective orders were violated in their study, when they were it was with significant reductions of violence and abuse. Logan \& Walker (2010) also found that victims were less fearful of future harm with a protective order in place and felt the protective order was fairly to extremely effective. Hawkins (2010) found that violence and abuse drastically declined after protective orders were issued. In contrast, two other studies found high rates $(32-60 \%)$ of re-abuse within 3 months to 1 year of filing a protective order. Differences in definitions of violence, sample characteristics, and participation make it difficult to draw any firm conclusions regarding the effectiveness of protective orders (Gist, McFarlane, Malecha, Fredland, Schlutz \& Wilson, 2001).

In fact, research indicates that $80 \%$ of women with temporary protective orders (77\% with permanent orders) reported contact with the abusive partner within 3 months following the order (Harrell \& Smith, 1996). Chaudhrui and Daly (1992) reported lower rates of contact (37\%) at two months. Studies that have measured recidivism rates find that during follow-up periods of between 6 months to 2 years, $24 \%-60 \%$ of women report further abuse (Chaudhuri \& Daly, 1992; Carlson, Harris, \& Holden, 1999). Kingsnorth (2006) found that the presence of a protective order predicted re-arrest for domestic violence with an 18-month follow-up period. In other words, domestic violence offenders who had protective orders in place against them were more likely than those offenders who did not to recidivate. Unfortunately, it is not known whether or not further abuse would have occurred within this time frame, even without a protective order. Harrell and Smith (1996) reported that among women who experienced further problems with the men in the orders, less than half called the police.

Regardless, interviews with victims of violence reveal that the benefits of protective orders may extend beyond legal redress. The court process appears to be empowering for many women. Having their abuser publicly admit to various acts of violence was satisfying for many women who experienced violence in their private lives. Interviews with women who filed protective orders find that $86 \%$ reported the orders were "somewhat" or "very" helpful in documenting that the abuse occurred, although fewer than half of the women believed their abusive partner "thought he had to obey" the order (Harrell \& Smith, 1996). Other women, however, experienced trauma at having to relive the violence they experienced a public setting and preferred giving the details to a judge in a more private setting (Chaudhuri \& Daly, 1992). Some have argued that because they do not involve criminal procedures, the victim may feel safer using these measures to protect themselves than criminal procedures which could cause the offender to retaliate out of anger or retribution (Trinch \& Berk-Seligson, 2002; Kethineni \& Beichner, 2009).

\section{Enforcement}

Research on the enforcement of protective orders also reveals mixed results. Research indicates that domestic violence calls are taken more seriously when there is a protective order in place. Furthermore, the arrest rates are higher for abuse calls that also violate protective orders. Although higher than other domestic violence calls, the arrest rate for protective order violations appears to be low, even in locations known for having aggressive domestic violence policies (Klein, 1996). One study shows that even when arrest occurs, the vast majority are dismissed without jail time or probation or not sentenced in full accordance with state and federal sentencing guidelines (Diviney, Parekh \& Olson, 2009; Klein, 1996). In one study, only $18 \%$ of arrestees for protective order violations were jailed (Klein, 1996). Moreover, studies in England, Canada, and the United States find that police are reluctant to arrest protective order violations largely due to the fact that they are civil injunctions, rather than criminal injunctions (Rigakos, 1997).

\section{Predicting Arrest}

Related to enforcement of protective orders is the issue of predicting arrest in domestic violence cases. A variety of situational, organizational, and personal characteristics appear to influence arrest decisions. Most studies have confirmed that incident-level factors appear to have the most impact on police response. Specifically, the more severe the violence, if there are injuries, and if there is a weapon present are the incidents more likely to end with an arrest (Bachman \& Coker, 1995; Belknap, 1995; Eitle, 2005). Other studies have found conflicting findings on extralegal factors influencing police arrest. For example, some studies have found victim-offender relationship being important (i.e. more likely to arrest if they are not married) (Belknap, 1995), while other studies have found the opposite (Dichter, Marcus, Morabito, \& Rhodes, 2011). Some studies have focused on police organizational factors (Chappell, MacDonald, \& Manz, 2006; Eitle, 2005; Finn, Blackwell, Stalans, Studdard, \& Dugan, 2004) and community factors (Logan, Walker, \& Leukefeld, 2001). A protective order in place may be an important variable in terms of predicting arrest.

This current study asks two general questions. First, in what ways do protective order violations differ from other domestic violence cases? Are they unique in some way such as likelihood of violence, relationship status of the offender and victim, or demographic characteristics? Protective orders 
are filed by victims with a pattern of threats or violence perpetrated against them by an intimate partner. It would be helpful to know if there are other factors, in addition to a history of violence or threats, that distinguish protective order calls from other domestic violence cases. Given that arrest will be compared in these two groups, this study also addressed the issue of enforcement of protective orders and ultimately, their effectiveness. Second, what factors predict whether or not an arrest is made comparing those cases with a protective order present to those cases without? It is important to understand what variables officers consider important when deciding to arrest. Is the type of abuse the deciding factor, or do other factors such as the relationship between the victim and offender, or the presence of the offender predict arrest? Factors to be considered are: relationship to offender and variables related to the incident (types of violence, alcohol or drug use present, offender present when police arrive, and so on). The goal ultimately is to aid police in their response and hopefully better serve victims in their attempts to deal with abuse they are experiencing at the hands of a current or former intimate.

\section{MATERIALS AND METHODOLOGY}

The data used for this paper were a combination of quantitative and qualitative data from a police department in a large, western metropolitan area in the United States. Included were all police-classified domestic disturbance incidents reported to the police in 2003. Data included information entered by the police into check boxes at the time the report was made as well as police narrative recoded by trained researchers. Only cases where the offender and the victim were involved in a current or former heterosexual relationship were included (thus child-parent, parent-child, sibling, roommates, and same-sex relationships were excluded) ${ }^{1}$. Moreover, cases where a protective order was being served, where police were escorting either the victim or offender to pick up possessions, or where multiple parties were involved (i.e. both intimate and non-intimate violence took place) were also excluded. The final study sample was composed of 1439 domestic disturbance cases. Of the 1439 cases of intimate partner abuse, 252 were protective order violations. This subgroup of calls to police is used for comparison purposes throughout the paper.

As stated above, both quantitative and qualitative data were used. The qualitative narrative that the police record after they respond to a call was combined with the already supplied quantitative data and recoded by trained researchers into the data $\operatorname{set}^{2}$. The researchers read the narrative and determined the victim-offender relationship, the types of behaviors in the incident, whether or not children were present or witness were present, and so on. Variables recoded in this manner and used in this analysis include: victim-offender relationship (in an intimate relationship at the time of the police response or not in an intimate relationship), offender present at the scene of the incident when police arrived, alcohol or drugs use present, victim scared for safety, evidence of verbal abuse, evidence of threats, presence and type of violence (using a modified Conflict Tactics Scale, CTS-(Straus, 1979), presence of and type of stalking (using the Stalking Behavior Checklist, SBC-(Coleman, 1997), whether or not the offender was arrested or issued a warrant for their arrest, and whether or not there was a protective order in place at the time of the incident. Each of these variables were coded (0) for no and (1) for yes. Variables included in the quantitative data provided by the police include gender and age of the offender. Descriptive univariate and bi-variate as well as multivariate analysis was employed, including crosstabulations using chi-square and logistic regression.

\section{RESULTS}

Table 1 presents the descriptive variables and the comparison for the two groups examined - those cases involving a domestic disturbance where there was not a protective order versus those where there was a protective order in place. Clearly, there are some significant differences between these two groups. First, there were a total of 1187 cases in which there was no protective order in place versus 252 cases in which there was a protective order in place. The cases in which there was no protective order in place were more likely to involve people currently in a relationship $\left(\chi^{2}=173.181 ; \mathrm{p} \leq 0.001\right)$, involve alcohol $\left(\chi^{2}=35.839 ; \mathrm{p} \leq\right.$ $0.001)$, physical violence $\left(\chi^{2}=145.708 ; \mathrm{p} \leq 0.001\right)$, verbal abuse $\left(\chi^{2}=83.726 ; p \leq 0.001\right)$, evidence that the victim was scared $\left(\chi^{2}=6.650 ; \mathrm{p} \leq 0.01\right)$, and have an offender present when the police arrived $\left(\chi^{2}=78.129 ; \mathrm{p} \leq 0.001\right)$. Those cases involving protective orders were more likely to have an offender and victim not in a current intimate relationship, involve threats to the victim $\left(\chi^{2}=4.033 ; \mathrm{p} \leq 0.05\right)$, have evidence of stalking $\left(\chi^{2}=598.852 ; \mathrm{p} \leq 0.001\right)$, and, perhaps most importantly, were significantly more likely to end up in an arrest compared to those cases where there was no protective order in place $\left(\chi^{2}=24.445 ; p \leq 0.001\right)$. In both cases, the offenders were most likely to be male and the means for the offenders were 34.0 and 37.2 respectively with a range from 18-80.

Table 2 presents the results of logistic regression for predicting whether or not the police arrested in each of the groups examined. Once again, there are some group differences. For the group with no protective orders in place, almost all of the variables predicted arrest. There were increased odds of arrest if there was alcohol or drugs present $(p \leq 0.01)$, violence $(p \leq 0.001)$, stalking $(p \leq 0.001)$, if the victim was scared $(p \leq 0.01)$, and if the offender was present when the police arrived $(p \leq 0.001)$. For the group that had protective orders in place, a different picture emerged in terms of what predicts arrest. The strongest predictor is whether or not the offender was present - the odds of arrest are increased if the offender was present $(\mathrm{p} \leq 0.001)$. Those odds are also increased if there was alcohol or drugs present $(\mathrm{p} \leq 0.001)$, stalking present $(\mathrm{p} \leq 0.05)$, and if the parties were still in a relationship $(\mathrm{p} \leq 0.01)$.

\section{DISCUSSION}

This study addresses two general questions about protective orders. First, in what way do protective order violations differ from other domestic violence cases and second what factors predict arrest in each of these groups? It is important to understand if the circumstances associated with the calls are qualitatively different. This is valuable information for the police responding to these calls. Also, 
Table 1. Comparing no protective order in place to cases with a protective order.

\begin{tabular}{|c|c|c|c|}
\hline Variable & No Protective Order $(n=1187)$ & Protective Order $(\mathbf{n}=\mathbf{2 5 2})$ & $\chi^{2}$ \\
\hline \multicolumn{4}{|l|}{ Relationship Variables } \\
\hline $\begin{array}{c}\text { Demographic Variables } \\
\text { Male Offender } \\
\text { Age (mean) }\end{array}$ & $\begin{array}{c}525(85.2 \%) \\
34.0\end{array}$ & $\begin{array}{c}186(90.3 \%) \\
37.3\end{array}$ & 3.389 \\
\hline $\begin{array}{l}\text { Offender Present at Scene } \\
\text { Alcohol/Drugs present }\end{array}$ & $\begin{array}{l}520(43.8 \%) \\
252(21.3 \%)\end{array}$ & $\begin{array}{l}35(13.9 \%) \\
13(5.2 \%)\end{array}$ & $\begin{array}{l}78.129 * * * \\
35.839 * * *\end{array}$ \\
\hline Physical Violence at Incident & $557(46.9 \%)$ & $15(6.0 \%)$ & $145.708 * * *$ \\
\hline Verbal Abuse & $711(59.9 \%)$ & $71(28.3 \%)$ & $83.726^{* * *}$ \\
\hline Evidence of Stalking & $174(14.7 \%)$ & $229(90.9 \%)$ & $598.852 * * *$ \\
\hline Arrest the Offender & $115(9.7 \%)$ & $52(20.6 \%)$ & $24.445^{* * * *}$ \\
\hline
\end{tabular}

Table 2. Logistic regression predicting arrest.

\begin{tabular}{|c|c|c|}
\hline & Model 1 No Protective Order & Model 2 Protective Order \\
\cline { 2 - 3 } & B(SE) & \\
\hline \hline Relationship Variable & & $1.266(0.436)^{* *}$ \\
\hline Currently in Relationship & $0.074(0.260)$ & \\
\hline Situational Variables & & $4.134(0.652)^{* * *}$ \\
\hline Offender present for police & $1.858(0.250)^{* * *}$ & $3.067(0.815)^{* * *}$ \\
\hline Presence of drugs/alcohol & $0.522(0.234)^{* *}$ & $0.162(0.581)$ \\
\hline Threats & $0.064(0.296)$ & $-0.611(0.569)$ \\
\hline Verbal Abuse & $-0.459(0.223)^{* *}$ & $-0.187(1.053)$ \\
\hline Physical Violence & $1.121(0.226)^{* * *}$ & $0.442(0.556)$ \\
\hline Victim Scared & $0.726(0.244)^{* *}$ & $2.347(0.931)^{*}$ \\
\hline Stalking & $1.261(0.337)^{* * *}$ & 0.316 \\
\hline
\end{tabular}

${ }^{*} \mathrm{p} \leq 0.05, * * \mathrm{p} \leq 0.01, * * * \mathrm{p} \leq 0.001$

this in part, represents an attempt to measure how enforced and effective protective orders are-one of their purposes is to assure that the police are holding offenders accountable. Finally, it continues to be important to explore those variables that predict arrest in incidents involving domestic violence and harassment.

Differences did emerge between the two groups. Relationship variables indicated that protective order cases were less likely to involve a couple engaged in a current intimate relationship. This makes sense give that protective orders are usually filed against a former intimate at time of break-up or after the relationship has ended. In a very symbolic sense, protective orders signify to the offender that the relationship is over. The protective order group was less likely to have the offender present when police arrived. Many protective order violations involved harassment by phone or at a distance, and so the offender was not present in the vast majority of cases. This is problematic because police officers often use offender presence as a variable when deciding when to arrest (see below). Physical violence and verbal abuse were also less likely with the protective order group. Several explanations could be used to explain these 
findings. The offender may simply not have much physical access to the victim and may use other abusive methods to continue harassment when physical proximity is limited. In regards to verbal abuse, this study did find that victims in the protective order group were more likely than those not to experience threats. Once again, this can be part of an offender's new strategy when their physical access to the victim is taken away. Moreover, many victims are advised by police to record every incident with the offender and document it thoroughly. The documentation of threats might be a consequence of this practice. Also, given that the offenders in the protective order group already have a history of abuse and/or harassment against this victim, they may be more mindful of the law and their behavior is more controlled in an effort to instill fear in the victim but not land themselves in jail. It is not uncommon for abusive patterns to adapt to new circumstances. Arrest was more likely among the protective order group. This indicates that police officers may be enforcing protective orders. This indicates that in some ways protective orders are achieving at least one of their purposes. However, although the rates were double that of non-protective order violation calls, only one-fifth of all protective order violations resulted in an arrest. This finding has some major implications. First, for the offender, protective orders may not have a deterrent effect. Deterrence theory argues that for a behavior to stop (or be deterred) action by police must be swift and certain. In the vast majority of cases, neither of these requirements is met. The offender may then feel that protective orders are meaningless or that they are simply a piece of paper if they are not enforced. If arrest is uncertain and even unlikely in the majority of cases, protective orders will not have a deterrent effect on the offender. Furthermore, this problem is exacerbated when police fail to go after the offender as noted above. Then the punishment is neither swift nor certain. There are also implications on the part of the victim of protective order violations. If protective orders do not deter the offender from unwanted contact, and the police fail to enforce the orders once they have been issued by a judge, then it is likely that victims will not view the police as helpful and may not utilize the criminal justice system to prevent further violence.

The second research question asked what factors predict arrest in protective order cases versus non-protective order cases. To address this question, logistic regression was used with arrest as the outcome. Once again demographic characteristics, relationship, and situational variables were analyzed and some differences emerged. Where there was no protective order in place, the following variables predicted arrest: offender present, presence of alcohol or drug use, physical violence, if the victim was scared, and if there was stalking at the incident. For the protective order group, the following variables predicted arrest: victim-offender relationship, offender presence, presence of alcohol or drugs, and whether stalking behaviors were present. The finding about offender present in both groups is important. Other research has also found that having the offender present when police arrive increases the likelihood of arrest (Feder, 1999; Hirschel \& Buzawa, 2013; Ho, 2000). It is possible that officers do not want to put the additional time and personnel into finding offenders who flee the scene or harass from a distance. However, this finding is particularly important given that the offender is significantly not likely to be present when a protective order is violated. This means that officers must be trained to utilize other variables in determining whether an arrest needs to be pursued or a warrant needs to be issued. Presence of offender at the scene should not be the strongest predictor of police action. The data indicates for both groups that the presence of drugs or alcohol to be a predictor of arrest. Previous research is mixed on drugs or alcohol as a predictor of arrest. Some studies find it contributes to arrest (Berk \& Loseke, 1980; Mignon \& Holmes, 1995) and others find it does not predict arrest (Erez, 1986; Feder, 1999; Ho, 2000). This inconsistency could be based on officers' own perception of alcohol as a contributor to domestic violence or departmental training could also play a role. In one study (Mignon \& Holmes, 1995) some departments reported a $100 \%$ arrest rates with alcohol use, others reported a $0 \%$ arrest rate. Finally, some significant variables predicted arrest in the non-protective order group that were not predictive in the protective order group - namely physical violence and whether or not the victim is scared. The presence of stalking did predict arrest in both groups. Interestingly, while the presence of verbal abuse was not a significant predictor of arrest with protective order violations, police were significantly less likely to arrest if there was verbal abuse but no protective order in place. This could indicate that police do not take as seriously cases involving verbal abuse where there is perhaps no obvious evidence of prior abuse. Having a protective order in place might signify to the police that there is at least a history of abuse.

Several policy implications emerge from this study. As mentioned earlier, police were more likely to make an arrest when a protective order was violated. This indicates that regardless of the effect of protective orders on recidivism (not explored in this paper), protective orders do have the effect of increasing the chances of police arrest in domestic violence situations. However, the vast majority of protective order violations did not lead to arrest. This may have implications for victims who are using the orders as protection and offenders who may not view the orders as a real threat. Police officers also made arrests based on whether or not the offender was present. Additional training and resources are needed to ensure that police do not use convenience or lack of resources as a reason to not follow through on these complaints. Finally, alcohol use was found to increase the arrest rate. It is possible that alcohol may reduce offender inhibitions and lead them to seek out their victims. Previous research has shown an indirect relationship between alcohol and abuse behaviors. Alcohol use itself does not cause violence, but may lessen the inhibitions of the offender. Police decision-making involves the officer's perception of the situation and alcohol use in this sample and may have led officers to perceive an increased threat to the victim.

\section{CONCLUSION}

Using police data to understand domestic violence has some limitations. The major limitation is that the data is dependent not only on what gets reported (i.e. much domestic violence is never reported), but also on how it gets 
reported by the responding officer. Police reports rely exclusively on an officer's report of the incident and are dependent on several factors such as the officer's reporting style, who was present at the time the police arrived and who the police interviewed. Some police narratives are very brief and others included very detailed information. For example, regarding reports that are more detailed, this does not necessarily mean that certain behaviors did not occur at the incident, it may just mean that certain police officers did not ask about them. One example would be drug or alcohol use present at the scene. The data is dependent upon the officers making note of this. This may only happen if it is obvious or one of the parties interviewed mentions it, but that does not necessarily mean that it was not present. Relatedly, police arrive after the incident has occurred, so they must recreate the incident in their notes based on information they receive from the victim, offender, and any witnesses. But, not all participants in a domestic incident are present when police arrive. In around half of all domestic calls the offender was not present when police arrived. Therefore, some of the reports may be recorded from the victim's perspective only. It should be noted that many variables are missing from the police data (i.e. offender/victim race/ethnicity, income, employment, etc...). Thus, these variables are not included in the analysis. Finally, while examining this issue using police reports and determining important relationships and correlations is important, it also is crucial to find out from police officers what they perceive themselves to use when determining action in domestic violence cases. Thus, future research on this issue very much needs to include the police voice. Police officers themselves are an important resource that should be used in an effort to fully understand police response to domestic violence. Regardless of the above limitations, it is important to empirically determine how police officers respond to domestic violence calls, in particular protective order violations. Police officers make the decision to arrest or not arrest involved parties at the scene, and it is crucial to know what factors come into play when police decide to arrest. Police data continue to be an important data source; they are a good source for understanding cases that come to the attention of the police, how police view and report cases, and the actions that the police take in dealing with domestic disputes.

In conclusion, all calls for domestic violence need to be taken seriously by law enforcement. Calls for protective order violations involve unique circumstances and should signal an increased risk for the victim. This study shows that police may take these violations more seriously than other domestic calls, although the overall arrest rate for this group was still low. To be more effective, arrest should be swift and certain. Neither of these requirements is met. Instead, offender presence was the greatest determining factor of arrest. In the end, calls for protective order violations and intimate partner abuse without a protective order in place both need an appropriate and adequate response.

\section{NOTES}

${ }^{1}$ IRB (\#12110) approval was granted to study those over 18.
${ }^{2}$ Over the course of the project, ten researchers/coders were involved in the coding of the qualitative data. Each coder received extensive training and a detailed codebook including a modified CTS and SBC scales. The coders met weekly to discuss cases and issues and were in constant contact via email. The first author closely supervised and checked the coders' work to ensure intercoder reliability.

\section{CONFLICT OF INTEREST}

The authors confirm that this article content has no conflict of interest.

\section{ACKNOWLEDGEMENTS}

Declared none.

\section{REFERENCES}

Bachman, R. \& Coker, A. (1995). Police involvement in domestic violence: The interactive effects of victim injury, offender's history of violence, and race. Violence and Victims, 10(2), 91-106.

Belknap, J. (1995). Law enforcement officers' attitudes about the appropriate responses to woman battering. International Review of Victimology, 4, 47-62.

Berk, S.F. \& Loseke, D.R. (1980). "Handling" family violence: Situational determinants of police arrest in domestic disturbances. Law and Society Review, 15(2), 317-346.

Bui, H'2 .N. (2001). Domestic violence victims' behavior in favor of prosecution. Women and Criminal Justice, 12(4), 51-76.

Carlson, M.J., Harris, S.D. \& Holden, G.W. (1999). Protective orders and domestic violence: Risk factors for re-abuse. Journal of Family Violence, 14(2), 205-226.

Chappell, A.T., MacDonald, J.M. \& Manz, P.W. (2006). The organizational determinants of police arrest decisions. Crime and Delinquency, 52, 287-306.

Chaudhuri, M. \& Daly, K. (1992). Do restraining orders help? Battered women's experience with male violence and legal process. In: Buzawa \& Buzawa (Eds.), Domestic violence: The changing criminal justice response (pp. 227-252). Westport, CN: Auburn House.

Coleman, F.L. (1997). Stalking behavior and the cycle of violence. Journal of Interpersonal Violence, 12 (3), 420-432.

Dichter, M.E., Marcus, S.C., Morabito, M.S. \& Rhodes, K.V. (2011). Explaining the IPV arrest decision: Incident, agency, and community factors. Criminal Justice Review, 36(22), 22-39.

Diviney, C.L., Parekh, A. \& Olson, L.M. (2009). Outcomes of civil protective orders: Results from one state. Journal of Interpersonal Violence, 24, 1209-1221.

Eigenberg, H.M. (2001). Woman battering in the United States: Till death do us part. Illinois: Waveland Press, Inc.

Eitle, D. (2005). The influence of mandatory arrest policies, police organizational characteristics, and situational variables on the probability of arrest in domestic violence cases. Crime \& Delinquency, 51(4), 573-597.

Erez, E. (1986). Intimacy, violence, and the police. Human Relations, 39(3), 265-281.

Feder, L. (1999). Police handling of domestic calls: An overview and further investigation. Women and Criminal Justice, 10(2), 49-68.

Finn, M.A., Blackwell, B.S., Stalans, L.J., Studdard, S. \& Dugan, L. (2004). Dual arrest decisions in domestic violence cases: The influence of departmental policies. Crime and Delinquency, 50, 565-89. 
Gist, J.H., McFarlane, J., Malecha, A., Fredland, N., Schlutz, P. \& Wilson, P. (2001). Women in danger: Intimate partner violence experienced by women who qualify and do not qualify for a protective order. Behavioral Sciences and the Law, 19, 637-647.

Goolkasian, G.A. (1986). Confronting domestic violence: The role of criminal court judges. National Institute of Justice, Washington, D.C.

Harrell, A. \& Smith, B.E. (1996). Effects of restraining orders on domestic violence victims. In Buzawa, E., \& Buzawa, C. (Eds.) Do arrests and restraining orders work? (pp. 214-242). Thousand Oaks, CA: Sage.

Hawkins, N. (2010). Perspectives on civil protective orders in domestic violence cases: The rural and urban divide. National Institute of Justice Journal, 266, 4-8.

Hirschel, D. \& Buzawa, E.S. (2013). The impact of offenders leaving the scene of the police decisions to arrest in cases of intimate partner violence. Violence Against Women, 19(9), 1079-1103.

Ho, T. (2000). Domestic violence in a southern city: The effects of a mandatory arrest policy on male-versus-female aggravated assault incidents. American Journal of Criminal Justice, 25(1), 107-118.

Kaci, J.H. (1992). A study of protective orders issued under California's Domestic Violence Prevention Act. Criminal Justice Review, 17(1), 61-76.

Keilitz, S., Hannaford, P. \& Efkeman, H. (1997). Civil protection orders: The benefits and limitations for victims of domestic violence (Publication No R-201) Williamsburg, VA: National Center for State Court Research.

Kethineni, S. \& Beichner, D. (2009). A comparison of civil and criminal orders of protection as remedies for domestic violence victims in a Midwestern county. Journal of Family Violence, 24, 311-321.

Kingsnorth, R. (2006). Intimate partner violence: Predictors of recidivism in a sample of arrestees. Violence Against Women, 12(10), 917-935.

Klein, A.R. (1996). Re-abuse in a population of court-restrained male batterers after two years: Development of a predictive model. In:
E. Buzawa \& C. Buzawa (Eds.) Domestic Violence: The Criminal Justice Response (pp. 192-213). Thousand Oaks, CA: Sage.

Logan, T.K., Nigoff, A. \& Walker, R. (2002). Stalker profiles with and without protective orders: Reoffending or criminal justice processing. Violence and Victims, 17(5) 541-553.

Logan, T.K., Walker, R. \& Leukefeld, C. (2001). Rural, urban influenced, and urban differences among domestic violence arrestees. Journal of Interpersonal Violence, 16, 266-83.

Logan, T.K. \& Walker, R. (2009). Civil protective order outcomes: Violations and perceptions of effectiveness. Journal of Interpersonal Violence, 24(4), 675-692.

Logan, T.K., \& Walker, R. (2010). Civil protective order effectiveness: Justice or just a piece of paper? Violence and Victims, 25(3), 332348.

McFarlane, J., Campbell, J., Wilt, S., Sachs, C., Ulrich, Y. \& Xiao, X. (1999). Stalking and intimate partner violence. Homicide Studies, 3(4), 300-316.

Mignon, S.I. \& Holmes, W.M. (1995). Police response to mandatory arrest laws. Crime and Delinquency, 41(4), 430-442.

Moracco, K.E., Andersen, K., Buchana, R.M., Espersen, C., Bowling, J.M. \& Duffy, C. (2010). Who are the defendants in domestic violence protection order cases? Violence Against Women, 16(11), 12011223.

Rigakos, G.S. (1997). Situational determinants of police responses to civil and criminal injunctions for battered women. Violence Against Women, 3(2), 204-216.

Straus, M.A. (1979). Measuring interfamily conflict and violence: The conflict tactics (CT) scales. Journal of Marriage and the Family, 41(1), 75-88

Trinch, S.L. \& Berk-Seligson, S. (2002). Narrating in protective order interviews: A source of interactional trouble. Language in Society, $31,383-418$.

(C) Melton and Nordmeyer; Licensee Bentham Open.

This is an open access article licensed under the terms of the Creative Commons Attribution Non-Commercial License (http://creativecommons.org/licenses/ by-nc/3.0/) which permits unrestricted, non-commercial use, distribution and reproduction in any medium, provided the work is properly cited. 